\title{
Creation of the Social Identity through the Dressing and the Representation of the Virtual Body in Virtual Internet Communities
}

\author{
Dr. Zoi Arvanitidou
}

PhD in Folklore and Fashion, University of the Aegean, Rhodes, Greece Email: arvanitidou@aegean.gr

\section{Doi:10.5901/ajis.2016.v5n3s1p233}

\section{Abstract}

\begin{abstract}
An avatar is a gamer's/participant's virtual representation and manifestation in a 3D virtual world such as Second Life, World of Warcraft and others. Different appearances of avatars have different effects in the communication and behavior of the participants in virtual public spaces, as participants with more elaborate avatars had greater success in virtual social contacts than those who used avatars with a "simple" appearance. The process of creating an avatar is influenced by the virtual world's social context where the participants act and react through their avatars. During the creation process the participants shape their avatars either like their actual appearance or nothing like it. The avatar's appearance causes confirmatory social behaviors, as participants react subconsciously to the social imperatives underlying the expected behavior based on the digital image's appearance. The appearance of the avatar affects the perception of the other participants with regards to the actual user behind the avatar, as their expectations of the social structures influence their behavior and they react to other avatars based on their digital appearance. So the reactions of others avatar constitute a behavioral response to the user of this avatar. Most users of virtual worlds create images that look like them, which lead to greater self-awareness of their body, and perceive their avatars as similar to their own reflection in the mirror. This permeates in the social interaction with an increased truthfulness in the representation of the individual characteristics of the participants, leading to effective contacts and interactions between users with more interpersonal confessions. Even digital worlds constitute a framework for experimentation in gender roles and a place for exploration of femininity and masculinity. It is really interesting that half of the female avatars used are actually male users.
\end{abstract}

Keywords: Dressing, Fashion, Gender, Virtual Worlds

\section{Introduction}

Digital virtual worlds provide space to groups of people who want entertainment or socialization. There are several different virtual worlds that offer games, others which simulate real life and others that offer training. Some well-known virtual worlds are Second Life, The Sims, the Dreamscape, the Maple Story, the World of Warcraft, etc. In Second Life, over 15 million users are connected and there are over 200 universities. It is used for online interactive discussion and social contacts, for observation and netnography, for simulation based training, as a virtual university classroom, as a conference room, etc (Jarmon, Lim, \& Carpente, 2009).

In digital worlds, a participant is represented by a 3D digital image known as an "Avatar" and it constitutes the visible digital identity. The word "Avatar" is Sanskrit, and means the incarnated form of a god on earth and was adopted to describe the digital images of people in online worlds with their dressing and their appearance (Damer, 1997). Avatar is a symbolic artifact that announces the presence of the user in the virtual world and unlike the anonymous online identity; it presents the user's desired individual properties during online communication. However, it is unclear how the other participants perceive the claimed properties and how they affect their online behavior (Vasalou, Joinson, \& Pitt, 2007)

Avatars permit concealment and anonymity of the users, but it is logical that the appearance and behavior of an Avatar reflects its user's conscious choices. Their available options in several virtual worlds allow users to select or build avatars that are either a realistic representation of themselves or a radically different one. But these avatars always reflect the personality and the character of their user and are created for a specific, desired version of the Self (Bailenson \& Blascovich, 2011).

\section{The Role of Avatars' Appearance in Social Contacts Within Digitals Worlds}

Social communication constitutes a key target - challenge within digital worlds, where people can "talk" with others and 
exchange opinions. In these 3D worlds the communication between various connected users is in real time and in this way social relationships develop. Apart from the text chat, commands of feeling's expressions are available for Avatars which give users the ability to use non-verbal forms of communication (Jones, 1998).

In real life, a person's external appearance affects his/her social acceptance and socialization. The external appearance includes primarily dressing, shoes and personal accessories as well as body characteristics (body type, weight, height, hair and skin color). Also it includes body postures, facial expressions, behavior and the degree of confidence transmitted. During online communication, the expectations for the character of participants are determined by the appearance of their Avatar (Jacobson, 1999). In real life, people experiment with their appearance by changing clothes and/or hair color and/or other characteristics. In digital worlds everyone can be represented through his/her Avatar as he/she desires by changing characteristics that are not easy to change in the real world such as skin color, body shape, weight, height etc. Even the appearance of the Avatar may indicate that he/she belongs to a group, as different groups use a uniform appearance (Manninen, 2003). For this reason users want to have a say in the construction, dressing, equipment and decoration of their Avatar. Thus the well - known digital worlds give this extra feature, and the users spend more time in selecting and improving their virtual appearance. Also for the formulation of experience, besides the general appearance of the Avatar, the level of details in which they presented plays a large role (Schroeder, 2002).

A survey of Banakou, Chorianopoulos and Anagnostou (2009) examined the consequences of the Avatar's appearance in the user's social interaction in virtual worlds. The conclusion was that the Avatar's external appearance is crucial during social contacts with other users and that those who used more elaborate avatars had more successful social contacts than others with avatars bearing a simpler appearance. Specifically a user reported that he chooses to talk with other users whose Avatars have an equally groomed appearance with his/her, because he/she thought that this happens also in real life. Another player commented that in digital worlds there are groups with specific costume features (rappers, yuppies, etc.) and their users prefer to communicate mostly with member of their team as they do in real life (Banakou, Chorianopoulos and Anagnostou, 2009).

The appearance of avatars causes the user's confirmatory behavior where someone reacts consciously to social imperatives that dictate how he/she should act in accordance with his/her appearance. This is the phenomenon where someone does so in accordance with the belief that the appearance of the Avatar indicates the expected behavior of his/her part. When the other users perceive an avatar as attractive they often approach it frequently and their conversations with it are warmer. Players would easily reduce interpersonal distance with attractive avatars and they made more revelations about themselves than through their interactions with avatars in strange appearance. Also users with taller Avatars exhibited more confidence in cases of negotiation, demanding more for themselves (Yee, Bailenson, \& Ducheneaut, 2006).

Users, depending on the appearance of their Avatars, are divided into four categories: a) The Realistics who are the most in terms of numbers and create anthropomorphic avatars similar to their physical appearance having the same sex as in real life. b) The Idealized who create avatars that are considered more attractive than their physical appearance by changing their weight, height, etc. c) The Role-players who usually use several avatars simultaneously and they do not link exclusively to one character during their stay in the virtual world. d) The Fictionals who create a completely original, fictional character, usually not anthropomorphic (fairy, dragon, animal such as dog, cat, etc.). The users in digital worlds when choosing how to configure their avatars, they are influenced by the social context of the world they enter. Jennifer Wu in her survey (2013) asked users to choose avatars representing them in various scenarios. They chose the realistic female avatar frequently than an idealized female avatar in an interview simulation job and frequently chose the form of a dog in a scenario based on alternative universes. All the above show that in digital worlds, people believe that in differential social situations they are obliged to harmonize their Avatar's appearance depending on the occasion (Wu, 2013).

\section{The Role of the Avatar's Appearance in the Formation of the Identity and Interaction with Real Body}

The appearance of the Avatar affects the degree of the user's comfort in the virtual world and affects his/her social interactions in a complex way. When he/she feels comfortable in the digital world and considers his/her Avatar as an extension of himself/herself, the sense of identity of this world is included in his/her true identity and completes it. When the participant feels that he/she is present in the digital world, he/she feels the Avatar of as an extension of him/her, so there is in this world and he/she thinks that the same happens with other users so he/she feels that coexists with them. Every user who creates an avatar, he/she does it because he/she has a need of an identity that either extend his/her 
offline identity, or build a new, completely independent one (Neustaedter \& Fedorovskaya, 2009).

The adaptation and decoration of an Avatar is a way of individual expression, so, that users spend much time on it. In most digital spaces, like Dreamscapes, offer «ready» prefabricated Avatars but if players only used the available ones then they would all have similar appearance. So, they adjust them in order to establish a unique identity which except of the aspect of personalization has also a social function, as these sophisticated Avatars are immediately recognizable and the other players remember them during the next few days. There were cases where users copy Avatars of other users but the digital community reacted strongly because this is considered a very serious offense in the digital world. The users' satisfaction depends on the extent that they can immerse themselves in the virtual world through their Avatar. They want to feel harmony being in the Avatar and the more this happens the more they identify themselves with their Avatar. This in turn is linked to the extent that they can create, view and execute the identity they wish. Most users agree that the creation of their first Avatar tries to express their presence in the digital area. During this stage they test various bodies, heads, color and accessories. Some of them do not feel comfortable with human bodies and heads and test these on of animals (cat, lion, dragon, etc.). In this way they try to gain more room to maneuver in the digital world, exempted from their human responsibilities as a defensive measure in order not to be 'reached' much by the other users until their intentions are clear. These processes are usually subconscious and users need some months to finally feel comfortable with human appearance which indicates that the appearance of the Avatar discloses aspects of the Self. The head is a basic piece that plays a significant role in the performance of the identity. Even the animal's head can create a sense of self and enable social connections, while simultaneously providing some detachment. When users become familiar with the digital world and gain friends, they start to use human heads. Then they verify that their interactions with others users are more substantial. Some users still use many heads depending on their mood or to experiment with the other user's reactions by studying how they affect their behavior and their level of comfort. Even objects and accessories like witch hats, helmets, crowns, etc. are used in an Avatar to present various aspects of the self.

One notable and curious aspect of this matter is that a number of users perceive their avatars as more real than their real body. They believe that in their Avatars they found a better version of themselves, where they feel more comfortable than in their actual bodies. Some of them experiment using various avatars and study the various types of their effects, as digital environments allow users to stand out of their digital selves and they can critically face conversations. These users are not particularly connected to their Avatars and they are interested to compare their online identities with the real ones. They are the most thoughtful of users who reflect the kind of self that they display and they perceive their Avatar as a tool for long-term exploration of the world and perhaps a mean of reconfiguration for themselves. Although the effective promotion of users is the active construction of their digital identity, they often report that their Avatars have some independence as they are outside their control and are virtually autonomous (Taylor, 2002).

Thus they admit that they cannot predict how their Avatar will behave in the different circumstances that will arise. In this case users express an awareness of the observation of the social construction of the identity and the body, which are possible due to the detachment from their Avatar. Especially in the digital world, the understanding of social context in digital image may be different from that which the user has predicted and the digital community can face the Avatar in a way that he/she has not predicted. This shows that identities and bodies have certain significance and are constructed from acceptance or challenge of the Avatars in a specific social context. Thus, the user concludes that the other users face him/her through how he/she presents himself/herself, which creates a change in him/her. The digital body competes with the physical body of the user which affects the ideal body (i.e. internalized representation of the body), and can significantly change. Avatars raise questions about what is the body, who we are and what we could be. Finally, roleplaying provides users with significant benefits as they experience behaviors that they do not dare to apply in real life, they measure the reactions of other users to consider how they feel and to reject them or to use them in real life (Taylor, 2002).

\section{The Game of Dressing Up in Digital Worlds}

In virtual world games, such as The Sims, Ever Quest, City of Heroes and Second Life, dressing and fashion play an important role especially for the women but also for men players as the computer, by inserting a technological dimension, eliminates their feminine complexion. As a Dressing Up game defined a series of practices where a person pretends, believe or make the others to believe that he/she is someone different from the real self. He/she hides, forgets or temporarily separates his/her personality to pretend to be someone else (Caillois, 2001). The difference between the digital dressing and the real one is that the first exists in the digital's world software and each garment that is available is a conscious choice of the developers who made this world. The extent on which users can intervene and transform 
clothes also depends on software (Fron, Fullerton, Ford Morie, \& Pearce, 2007).

According to the relationship between players, costumes and characters of the game distinguish two ways of dressing: a) The user dresses his/her Avatar in a way that does not represent him/her and in which he/she has absolute power. b) The user displays his/her real self through the Avatar and his/her personal choice and configuration of the costume expresses an identity. Especially in role-playing games, players must choose a social class, gender and name. This membership in a group determines the appearance of player's Avatar what it is permitted to wear and how his/her appearance may evolve in the game. In fiction games with medieval themes the dressing except from personal expression is a crucial component of the game that is organically linked to the performance of each character (Fron, Fullerton, Ford Morie, \& Pearce, 2007).

\section{Methods of Acquisition Clothes and the Role of Fashion in Virtual Worlds}

The manner of dressing acquisition in the digital world significantly determines the development of each game. For example, in The Sims and There.com players can buy clothes from some auction pages within the game or from other fan made websites. In There.com it is possible for the user to try clothes so that other players judge them and express their opinion whether they like it or not. In World of Warcraft dressing is a key tool and clothes are acquired as spoils of war, or users can buy them from others. Players can construct clothes if they gather the necessary materials (linen, silk, etc). In There.com there is a comprehensive mechanism for dressing manufacturing and the players of this digital world award the best clothes. There are various levels - categories: the Explorer, the Hoverboarder, the Fashionistas, the Sosializers and any player who changes or buys clothes goes to a higher level. Players can design fashion items, but they must pay to expose them for sale in the game's service website. In There.com they bypass restrictions on clothes combination, which the program of the game contained and while initially skirts were not available, players achieved to create them with different ways. When software was modified and they were in common use they were coveted and expensive. In Second Life and in There.com a user can donate or lend his/her clothes to someone else. From all the virtual games, The Sims promotes fashion more as shown by the many websites that sell clothes for The Sims characters, which are designed by players. For this reason it has gathered numerous female players. But also men players, like the women, perceive in The Sims fashion design as a productive game (Fron, Fullerton, Ford Morie, \& Pearce, 2007).

In Second Life each participant can design, create clothes for his/her use, or open a store and sell them to other players using a virtual currency. The creators of this virtual world allow players to design anything they want and keep the intellectual property of their creations. There are software tools for the change of the Avatar's appearance, but the digital natives introduced other tools also in order to construct the persona which they wish. Therefore imaginary species were created with horns, tails, strange hairstyles and a lot of hands or feet. Fancy clothes which the users of virtual worlds design could not exist in reality as the game can bring technology, such as animations, flashes, lighting, elaborate geometric patterns and other special effects. There are not extensive researches regarding the financial results of the digital fashion industry. Chung's survey (2005) showed that players who are closely connected with their Avatars buy fashion and cosmetics more than the others. Also Tyler (2013) points out that those women players with ambiguous attitude towards their Avatar do not invest in digital fashion. Fashion is probably the sleeping economic giant in dressing up games of virtual worlds.

\section{Participation in Digital Worlds from a Gender Perspective}

It is estimated that women's participation in role-play games are about 10 to $20 \%$. Some of them choose the female warrior role, but others prefer stereotypical female roles as nurse, seamstress or herb therapist, experimenting with different personality types in the context of interdependence of the digital world. Women report enjoying these roles as those who are not dynamic in their real life show strength in the virtual world. Of course the same happens with male players. Those who suffer from social phobias can grow stronger in the framework of virtual games. Also women enjoy organizing events in virtual communities and pursue trading. Women are better fashion designers especially in Second Life and in There.com where they are much more than men designers and they enjoy social recognition and economic prosperity in the digital world (Taylor, 2003). 


\section{Gender Game Equality in Digital Worlds}

These digital worlds allow for experimentation and the test of different gender roles in certain social contexts. Players can explore competition issues of gender, femininity and masculinity issues as they are better aware of who they are (Brunner, Bennett, \& Honey, 1998). In digital worlds men and women experiment with extreme gender expressions and there is no discomfort for gender, homosexuality and especially the last one is used by heterosexual men players. It is noteworthy that while around $50 \%$ of Avatars have female figure in role playing games only $10-20 \%$ of the players are women which means that more than half avatars - women are used by men, something that occurred in all age groups which is culminating in men from 22-35 years. The interpretations for this behavior are: a) In real life the boundaries of gender are very strict for men and thus they find an opportunity to experiment with gender roles in virtual worlds. b) In these digital environments women Avatars are treated more favorably. c) Men may perceive it as an alternative form of domination over the female body. d) In competition games between two players, the weak female Avatar, perhaps gives the advantage of surprise to the male user against an unsuspecting chauvinist opponent (Yee, 2003). Perhaps even men use female Avatars because they have more beautiful appearance. The digital world makes the dressing up game more acceptable socially for men. Some male players use female Avatars to design women's clothes because of the greater range of women's fashion choices in digital games. The cross - gender game gives new ways of individual expression. In There.com there is the peculiarity that players use their real voice for communication rather than text chat, like in the most virtual worlds. In general men users who have female avatars use their male voices and it is usual for female avatars to speak with a male voice. This of course creates a gender transparency and a particular culture in the game (Pearce, 2006).

As for the hyper sexualized dresses (eg leather bikini) with which female Avatars are presented in digital battles is a male (and not a female) structure that reveals the male fantasy of how they prefer women (Taylor, 2002). In digital places where the Avatar's dressing has no restriction fashion operates as a personal expression and method of exploration of social gender identity. Although some female players complain about the female Avatar's appearance with Barbie doll proportions but they do not lose the opportunity to modify the breast size, weight and age of their Avatar. Somebody would expect that women users would not want too sexualized Avatars but these in contrast dress their Avatars with sexier clothes than they often use for themselves in real life taking advantage of the anonymity of the digital worlds and the opportunity to showcase a perfect body expressing how they wanted to be in real life. Perhaps this is due to the sense of women's safety in these areas where sexual attacks are indirect and there is no physical hazard (Fron, Fullerton, Ford Morie, \& Pearce, 2007).

\section{On Anthropomorphic Avatars}

The user's representation through an Avatar in digital worlds is based on the assumption that it must have human appearance or at least display human behavior. Usually some degree of anthropomorphism is used in the design of the Avatar (ie human characteristics and properties), under the assumption that this is conducive to social interaction. But more and more frequently users use non-human Avatars inspired by legends (dragons, vampires), mythology (Minotaur), the animal kingdom (butterflies, cats, dogs) even purely imaginary creatures which users do not expect them to act humanly. The interaction with these kinds of avatars may require new ways and manners but their identity can change and determine new ways of existence when interaction is based on non-human forms. The questions which arise (and which have not been investigated yet) are: what motivates people to want to represent themselves by such Avatars? Is there another deeply hidden self whom users feel safe to reveal in the anonymity of the digital world? Do they do this to get other users' attention? Even philosophical questions present for the performance of the self with such Avatars and how they affect the identity and behavior of the users. Non anthropomorphic Avatars challenge and expand the well known principles of communication and maybe create new ones. While other users know that there is a human being behind these Avatars and so their behavior will have human aspects the question established is whether all this affects the way of addressing the real body. In role-playing games people want new mental context, different from the everyday one and they impersonate a completely new person (persona). This in the real world occurs in some, institutionalized periodic activities (carnival, renaissance festivals, etc.). But, in the digital worlds such odds are constantly changing and perhaps they may change in a permanent manner the way one addresses the Self. Users of non-anthropomorphic Avatar can perform consistently a role and they develop the character directly in the virtual world. For example in Second Life there are fictional races (groups) with different ideologies and social structures and before the accession of an Avatar in a race, it must know the race's social interaction rules, permitted behaviors, actions, expressions and it must agree with 
them in a social contract which creates strong social responsibilities. The non anthropomorphic Avatars introduce new ways to build identities and new types of interactions, different from those of the real world. The identities that are created perhaps are fluid and chimerical but it seems that many users in the virtual world like to keep them.

\section{Conclusion}

The effect of the appearance of avatars is decisive for the outcome of social interaction and communication in digital worlds. The more elaborate and attractive Avatars are treated more favorably and achieve more and more substantial social contacts. Participants create avatars that look like their actual appearance or are completely different in the context of research, expansion and completion of their individual identity and this determines the kind of experience that they will accrue from the virtual world. The Avatar's appearance communicates to other users something from the self of the actual user, who he/she is and they help in the deeper awareness of the self. Virtual world experiences can reshape the user's feelings for their body. The online identities impact real life and the participants may feel their avatar as an extension of themselves or as something they do not like very much. The game of dressing up has deep roots in human culture and within the age of virtual worlds, it plays a very important role in its activities. The appearance and the clothes of Avatars can cross the gender boundaries, and they cover instinctive needs of the users to express hidden aspects of their personality. Generally Avatars are a means of exploration of the physical body but also of the personality that users idealize on the appearance of their Avatars. Finally, non-anthropomorphic avatars challenge and expand the boundaries of human behavior and expand interaction and communication capabilities.

\section{References}

Bailenson, N., \& Blascovich, J. (2011). Virtual Reality and Social Networks Will Be a Powerful Combination: Avatars will make social networks seductive. IEEE Spectrum.

Banakou, D., Chorianopoulos, K., \& Anagnostou, K. (2009). Avatars' Appearance and Social Behavior in Online Virtual Worlds. 13th Panhellenic Conference on Informatics (pp. 207-211). Corfu: IEEE.

Brunner, C., Bennett, D., \& Honey, M. (1998). Girl Games and Technological Desire. In H. Jenkins, \& J. Cassell, From Barbie to Mortal Kombat: Gender and Computer Games (pp. 72 - 87). Cambridge: MIT Press Cambridge.

Caillois, R. (2001). Man, Play and Games. Illinois: University of Illinois Press.

Chung, D. (2005). Something for Nothing: Understanding Purchasing Behaviors in Social Virtual Environments. CyberPsychology \& Behavior, 8 (6), pp. 538 - 554.

Damer, B. (1997). Avatars: Exploring and Building Virtual Worlds on the Internet. San Francisco: Peachpit Press.

Fron, J., Fullerton, T., Ford Morie, J., \& Pearce, C. (2007). Playing Dress-Up: Costume, Roleplay and Imagination. Proceedings: Philosophy of Computer Games, (pp. 1-23). Reggio Emilia.

Jacobson, D. (1999). Impression Formation in Cyberspace: Online Expectations and Offline Experiences in Text-based Virtual Communities. Journal of Computer-Mediated Communication , 5 (1), pp. 1-12.

Jarmon, L., Lim, K., \& Carpente, S. (2009). Pedagogy, Education and Innovation in Virtual Worlds. Journal of Virtual Worlds Research, $2(1)$, pp. $1-9$.

Jones, S. (1998). Cybersociety 2.0: Revisiting Computer-Mediated Community and Technology . London: SAGE.

Manninen, T. (2003). Interaction Forms and Communicative Actions in Multiplayer Games. The International Journal of Computer Game Research , 3 (1), p. http://www.gamestudies.org/0301/manninen/.

Neustaedter, C., \& Fedorovskaya, E. (2009). Presenting Identity in a Virtual World Through Avatar Appearances. Proceedings of Graphics Interface 2009 (pp. 183-190). Toronto: Canadian Information Processing Society.

Pearce, C. (2006). Seeing and Being Seen: Presence and Play in Online Virtual Worlds. Online, Offline \& The Concept of Presence When Games and VR Collide (pp. 1-2). Los Angeles: USC's Centers for Creative Technologies.

Schroeder, R. (2002). The Social Life of Avatars. London: SAGE.

Taylor, T. (2002). Living Digitally: Embodiment in Virtual Worlds. In R. Schroeder, The Social Life of Avatars: Presence and Interaction in Shared Virtual Environments (pp. 40-62). London: Springer.

Taylor, T. (2003). Multiple Pleasures: Women and Online Gaming. Convergence: The International Journal of Research into New Media Technologies, 9 (1), pp. 21 - 46.

Vasalou, A., Joinson, A., \& Pitt, J. (2007). Constructing my Online Self: Avatars that Increase Self-focused Attention. Proceedings of the SIGCHI Conference on Human Factors in Computing Systems (pp. 445-448). San Jose: ACM.

Wu, J. (2013). Choosing my Avatar \& the Psychology of Virtual Worlds: What Matters? Kaleidoscope, 11 (89), pp. 2-9.

Yee, N. (2003, September 3). Daedalus Project. Retrieved from http://www.nickyee.com/daedalus/archives/print/000551.php

Yee, N., Bailenson, N., \& Ducheneaut, N. (2006). The Proteus Effect: Implications of Transformed Digital Self Behavior. Communication Research , 36 (2), pp. 285 - 312. 